\title{
Pigmented Nevus
}

National Cancer Institute

\section{Source}

National Cancer Institute. Pigmented Nevus. NCI Thesaurus. Code C27816.

A nevus characterised by the presence of excessive pigment. 